\title{
Psychological Aspects of Anterior Cruciate Ligament Injuries
}

Clare Ardern, Joanna Kvist and Kate E. Webster

\section{Linköping University Post Print}

\section{Tweet}

N.B.: When citing this work, cite the original article.

Original Publication:

Clare Ardern, Joanna Kvist and Kate E. Webster, Psychological Aspects of Anterior Cruciate Ligament Injuries, 2016, Operative techniques in sports medicine, (24), 1, 77-83.

http://dx.doi.org/10.1053/j.otsm.2015.09.006

Copyright: WB Saunders

http://www.elsevier.com/

Postprint available at: Linköping University Electronic Press

http://urn.kb.se/resolve?urn=urn:nbn:se:liu:diva-126832 


\section{Psychological aspects of ACL injuries}

Clare L. Ardern, PT, $\mathrm{PhD}^{1}$; Joanna Kvist, PT, $\mathrm{PhD}^{2}$; Kate E. Webster, BSci(Hons), $\mathrm{PhD}^{3}$

${ }^{1}$ Postdoctoral Research Fellow, School of Allied Health, La Trobe University, Melbourne, Australia; and Division of Physiotherapy, Linköping University, Linköping, Sweden

${ }^{2}$ Professor, Division of Physiotherapy; Linköping University, Linköping, Sweden

${ }^{3}$ Associate Professor, School of Allied Health, La Trobe University, Melbourne, Australia

Corresponding author

Dr. Kate Webster

Department of Community and Clinical Allied Health

College of Science, Health \& Engineering

Health Sciences 3 building

La Trobe University

Kingsbury Drive

Bundoora

AUSTRALIA 3086

E. k.webster@latrobe.edu.au

P. +61 394795796

F. +61 394795737 


\section{Abstract}

2 Impairment-based evaluation has, until recently, been the mainstay of orthopaedic

3 research in anterior cruciate ligament (ACL) reconstruction. However, participation-

4 based outcomes, in particular returning to sport, have lately garnered increased

5 research attention. This is important because returning to sport is typically a main

6 concern of injured athletes. Recent meta-analyses have demonstrated that the return to

7 sport rate after ACL reconstruction is disappointingly low, and that a range of

8 contextual factors including age, sex, sport participation level and psychological

9 factors may affect the return to sport rate. Moderate to large effect sizes have been

10 demonstrated for greater psychological readiness to return to sport, and lower fear of

11 re-injury favouring returning to the pre-injury level sport after ACL reconstruction.

12 Understanding the relationship between psychological factors and returning to sport is 13 essential in light of the fact that most athletes recover good physical function after

14 surgery, and many athletes with good knee function do not return to sport.

15 Psychological factors are potentially modifiable with appropriate intervention, yet

16 these factors are not systematically addressed in routine post-operative rehabilitation.

17 This review summarises the recent evidence for the relationship between

18 psychological factors and ACL injury, including recovery from injury and returning

19 to sport. 
20 An anterior cruciate ligament (ACL) rupture is one of the most common sports-

21 related injuries to the knee. ${ }^{1}$ In contemporary orthopaedics, athletes who wish to

22 return to sport are typically advised to have ACL reconstruction surgery plus post-

23 operative rehabilitation to facilitate a safe return to sport; ${ }^{2,3}$ and are usually absent

24 from sports participation for between 6 and 12 months after surgery. ${ }^{4}$

25 A ruptured ACL was once considered career ending for athletes. ${ }^{5}$ With the

26 introduction of non-invasive surgical techniques and accelerated rehabilitation

27 protocols, ${ }^{6}$ knee function outcomes improved, and with this came increased

28 expectations of a successful return to the pre-injury level of sports participation.

29 Patients also have high expectations of ACL reconstruction in terms of recovery of

30 knee function, ${ }^{7}$ conceivably driven by continual advances in surgery and

31 rehabilitation, and media coverage. ${ }^{8}$ To meet these expectations of function and

32 participation requires considerable commitment to rehabilitation, and being mentally

33 prepared for an extensive and involved recovery period. ${ }^{9}$

34 Until recently, the focus of orthopaedic research in ACL reconstruction has been on

35 evaluating impairment-based outcomes after surgery. This is despite the fact that a

36 key concern for athletes is returning to participation in sport, and a lack of association

37 between knee impairments and function. ${ }^{10,11}$ Many athletes with good knee function

38 do not return to their previous level of sports participation after ACL reconstruction, ${ }^{12}$

39 and the rate of return to the pre-injury level and competitive sport is disappointingly

40 low. ${ }^{13}$ This has led researchers to question whether there are other factors that may

41 impact on returning to sport after surgery.

42 After injury, athletes often report anger, depression, anxiety, a lack of confidence and

43 fear of sustaining a new injury. ${ }^{14,15}$ There is also evidence that these psychological 
44 disturbances may affect recovery ${ }^{16-18}$ and returning to sport, ${ }^{16,19}$ as well as increase

45 the risk of sustaining a new injury. ${ }^{20,21}$ Recovery from sports injury is influenced not

46 only by physical factors, but also by psychological factors. ${ }^{19,} 22$ This means that to

47 successfully transition back to sport after injury athletes need to be physically as well

48 as psychologically ready; yet these states often do not coincide. ${ }^{19,22}$

49 There has been increased research attention paid to evaluating the impact of

50 psychological factors on outcomes after athletic injury. Therefore, the aim of the

51 present review was to review and summarise the evidence for associations between

52 psychological factors and returning to sport following ACL reconstruction.

\section{Theoretical perspectives}

54 Dysfunctional psychological responses to injury are hypothesised to persist due to

55 combinations of and interactions between biological, environmental, and psychosocial

56 factors. ${ }^{23}$ Similarly, returning to sport after injury is complex and multifactorial -

57 directly and indirectly influenced by a range of physical, contextual and psychological

58 factors (Figure 1). ${ }^{13,19,24-26}$ To account for the myriad factors and complex

59 relationships between these factors, biopsychosocial models have been proposed. ${ }^{18,27}$

60 In these models, psychological factors are hypothesised to have a central mediating

61 role on physical factors (impairments of body structure including muscle strength,

62 pain, stability, swelling and movement), social/contextual factors (e.g. recovery

63 expectations and quality of life), functional performance (including aspects of motor

64 control such as balance), and ultimately on returning to sport (Figure 1). A strength of

65 the biopsychosocial model is that it specifies pathways through which psychological

66 factors impact on treatment outcomes. ${ }^{28}$ In addition, the characteristics of an injury,

67 such as the cause, severity, and type; and sociodemographic factors, such as age, sex, 
ethnicity and socioeconomic status, are hypothesised to indirectly influence returning to sport via their impact on physical, psychological and social/contextual factors

(Figure 1). The potential for psychological factors to influence returning to sport after injury via a range of different pathways is illustrated in Figure 1, and underscores the importance of understanding and addressing psychological factors as part of the management of ACL injury.

Figure 1 about here

\section{Psychological response to athletic injury}

An athlete's response to psychological stress is hypothesised to play a major role in injury occurence; ${ }^{29}$ and the perception of stress is likely to be influenced by a range of athlete-related factors including personality, available coping resources, and history of stressors (both physical and psychological). ${ }^{29,} 30$ The athlete's psychological stress response may also continue long after the injury has occurred. ${ }^{31-33}$ Subsequently, the response to stress influences the athlete's cognitive appraisal of their injury. ${ }^{18}$ The cognitive appraisal directly affects an athlete’s emotional response and ultimately their behaviour. ${ }^{18}$ Therefore, the chain of psychological sequelae to injury could conceivably have an impact on rehabilitation and return to sport outcomes. For example, effective coping strategies could translate to an improved prognosis for recovery if the athlete is more adherent to rehabilitation, and as a result, able to return to function faster and with fewer debilitating psychological responses. ${ }^{18,27}$

Heightened negative emotional responses, including shock, frustration, depression, boredom, tension and anger, have been reported immediately after athletic injury ${ }^{34-36}$ and during recovery from injury. ${ }^{34,35,37,38}$ Conversely, injury may also be associated with positive emotions, with some injured athletes reporting feeling relieved after 
sustaining an injury because they are no longer under pressure to perform. ${ }^{18}$ The psychological response may also be linked to athletes' sense of athletic identity, with

94 athletes who were more involved in their sport conceivably having a stronger emotional response to athletic injury as a result of their greater investment in sports participation. $^{14,36,39}$

In a study of professional Australian Rules Football players, those who had severe injuries that potentially threatened their future performance or career reported a stronger negative psychological response compared to those who saw their injury as more minor. ${ }^{36}$ The nature and duration of the injury were key factors that impacted on

101 athletes' psychological responses to injury, along with a perception of isolation from

102 the team while undertaking rehabilitation, being sidelined from the team and the 103 game, and the extent of social support from medical staff, team mates and family. ${ }^{36}$

104 In the early post-operative phase after ACL reconstruction, significant reductions in 105 kinesiophobia and pain catastrophising, and significant increases in self-efficacy for 106 rehabilitation have been demonstrated. ${ }^{40}$ The increase in self-efficacy was found to be 107 associated with a reduction in knee pain intensity. Improved self-efficacy and reduced 108 kinesiophobia were also associated with improved knee function. ${ }^{40}$ These findings 109 suggest that psychological factors may have an important influence on recovery early 110 after ACL reconstruction; although this is not to discount the likely impact of early 111 physical recovery on psychological responses. The findings also suggest that

112 psychological interventions, particularly aimed at addressing self-efficacy and

113 kinesiophobia early in the post-operative phase, may have the potential to contribute 114 to improved short-term rehabilitation outcomes after ACL reconstruction. 
115 How do psychological factors influence sport injury rehabilitation?

116 Recovery of sufficient physical capacity to safely participate in sport after injury is

117 vital, and well addressed by physical rehabilitation. ${ }^{41}$ Systematic reviews have shown

118 that the majority of patients achieve good physical recovery after ACL

119 reconstruction, ${ }^{12}$ based on standard outcomes that measure aspects of function

120 important for successful performance of sport. ${ }^{42}$ Key milestones in rehabilitation after

121 ACL reconstruction are restoration of knee joint motion and muscle function,

122 independent function in daily activities including employment, sport-specific training,

123 and re-establishment of an athletic identity. ${ }^{43}$ Although the primary concern of most

124 athletes is returning to sport.

125 Psychological responses are prominent during rehabilitation, and make an important

126 contribution to the overall quality and progression of rehabilitation. ${ }^{28,39}$ Emotions

127 change over time during the rehabilitation period, ${ }^{34,37}$ and the emotional response has

128 been linked to an individual's sense of athletic identity. ${ }^{39}$ While negative emotional

129 responses immediately after the injury have been reported, ${ }^{34}$ the literature

130 demonstrates a consistent improvement in psychological responses as rehabilitation

131 progresses. However, for some athletes, the response may become more negative

132 around the time of clearance to return to sport and when they are making the

133 transition back to sport. ${ }^{14,34}$

134 Morrey et. al. ${ }^{34}$ found that athletes' emotional responses to ACL injury and

135 reconstruction followed a U-shaped progression through rehabilitation, with peaks in

136 the negative responses immediately following injury and at the time of clearance to

137 return to sport (at 6 months post-operative). In contrast to Morrey’s et. al. ${ }^{34}$ findings

138 of a U-shaped emotional response, Langford et. al. ${ }^{37}$ found athletes' emotional 
responses and psychological readiness to return to sport improved linearly over time

140 during rehabilitation, and psychological readiness to return to sport at 6 months after

141 surgery predicted returning to the pre-injury level sport at 1 year. Self-efficacy has

142 also been found to significantly improve as people progress through post-operative

143 rehabilitation, ${ }^{44}$ and there are correlations between self-efficacy and knee symptoms

144 and function (measured with the Knee Injury and Osteoarthritis Outcome Score) after

1453 , 6, and 12 months of rehabilitation. ${ }^{44}$

\section{How do psychological factors influence returning to sport?}

147 Athletes undergoing ACL reconstruction and their treating clinicians typically expect

148 a successful return to sport to following surgery. ${ }^{7,45,46}$ However, while surgery

149 addresses the underlying impairments in knee function, this does not always translate

150 to a successful return to sport ${ }^{13}$ - one in every three athletes do not return to their pre-

151 injury level sport after surgery. ${ }^{13}$ Non-modifiable contextual factors have been found

152 to be associated with returning to the pre-injury level sport following ACL

153 reconstruction, including being young, male, and playing elite level sport prior to

154 injury. ${ }^{13}$ Psychological responses are potentially modifiable factors that have also

155 been shown to be associated with returning or not returning to the pre-injury level

156 sport after surgery. Psychological factors may conceivably be modifiable with

157 specific interventions, and it could be hypothesised that addressing these factors could 158 have an impact on returning to sport. ${ }^{13,24}$

159 The extent to which an individual feels their engagement in a particular behaviour is

160 freely chosen, that they have the necessary competence to successfully complete the

161 behaviour, and perceive a meaningful connection to others as a result of engaging in a

162 behaviour is theorised to directly impact on the likelihood of an individual engaging 
163 in a behaviour. ${ }^{47}$ These autonomy, competence and relatedness constructs, when

164 fulfilled, increase self-motivation to engage in a particular behaviour. ${ }^{47}$ When applied

165 to the return to sport context, there is evidence that athletes who feel they have greater

166 personal control over their return to sport (autonomy), have greater confidence in their

167 body (competence), and feel more socially connected to teammates (relatedness) are

168 more likely to return to their previous level of sport. ${ }^{19}$ In addition, motivation,

169 confidence, self-efficacy, optimism and lower fear of a new injury are psychological

170 factors that have been associated with the likelihood of returning to the pre-injury

171 level following athletic injury ${ }^{3}$ and ACL reconstruction. ${ }^{25,}$ 26, 39

172 Anxiety about the risk of sustaining a new injury has been identified as a prominent

173 emotional response of athletes around the time that they are transitioning from

174 rehabilitation back to full participation in sport after serious injury. ${ }^{14,48}$ Emotional

175 responses are particularly powerful for athletes who sustain a serious injury, ${ }^{14}$ and are

176 a strong influence on an athlete’s decision to return to sport or not. ${ }^{49-51}$ While some

177 athletes use fear as a motivation during the return to sport transition, with the fear

178 dissipating when the injured body part is tested and holds up in competition; for

179 others, the fear of a new injury can hinder their return to sport. ${ }^{23,52}$ While poor or

180 inadequate rehabilitation after ACL reconstruction may negatively impact returning to

181 sport as athletes may lack the physical capabilities to safely and effectively participate

182 at their optimum level, the most common reason that athletes give for not returning to

183 their previous level of sport after surgery is fear of sustaining a new injury. ${ }^{12}$ Adding

184 further weight to the notion of fear of re-injury being a key psychological factor

185 impacting on returning to sport after ACL reconstruction, a recently published meta-

186 analysis demonstrated a moderately large effect (standardised mean difference 0.7) 
187 for low fear of re-injury (measured with the Tampa Scale for Kinesiophobia ${ }^{53}$ )

188 favouring returning to the pre-injury level sport following surgery. ${ }^{24}$

189 Meta-analysis has demonstrated large effects (standardised mean difference 0.9) for 190 psychological readiness to return to sport (measured with the ACL-Return to Sport

191 after Injury scale ${ }^{54}$ ) favouring returning to the pre-injury level sport after surgery. ${ }^{24}$ In 192 a recent qualitative investigation by Podlog et. al., ${ }^{55}$ psychological readiness to return 193 to sport was suggested by athletes to be multi-dimensional and comprise three key 194 dimensions that increased their perceived likelihood of successful return: confidence 195 in returning to sport, realistic expectations of sporting capabilities, and motivation to 196 regain the pre-injury performance standards. ${ }^{55}$ Athletes reported that their confidence 197 to return to sport was strongly influenced by their belief in the rehabilitation they 198 completed, their perception that the injured body part was completely healed and no 199 longer susceptible to re-injury, and that performance at the same pre-injury level was 200 possible. ${ }^{55}$

201 Given the prospective associations between psychological factors and returning to 202 sport, it may be reasonable to hypothesise that addressing psychological factors 203 during rehabilitation could be a way to help injured athletes maximise their chances of 204 returning to the pre-injury level sport. However, current rehabilitation after ACL 205 reconstruction focuses on physical recovery and helping athletes recover the physical 206 capacity to participate in sport. Despite this, many do not return to sport. Therefore, a 207 re-evaluation of current rehabilitation programs may be needed to incorporate 208 interventions that address confidence and psychological readiness to return to sport 209 after surgery. 
210 Competitive athletes reported that recovery of physical capacity to manage a return to

211 sport was a key part of building confidence to return, ${ }^{55}$ suggesting an inter-

212 relationship between physical and psychological readiness to return to sport. This

213 supports the notion that to optimise the likelihood of returning to sport, rehabilitation

214 should systematically address both physical and psychological factors. ${ }^{24,56}$

215 Interventions to address psychological factors could conceivably influence an

216 athlete’s confidence. For example, goal setting, education, modelling and rapport

217 building strategies could help to improve self-efficacy of rehabilitation and

218 confidence in the injured knee. ${ }^{19,38,55,57}$ Imagery and relaxation training may help to

219 allay fears of re-injury and improve self-confidence in performance. ${ }^{19,38,55}$ On the

220 other hand, it could also be argued that facilitating athletes' return to high demand

221 activities, such as pivoting sports, by addressing psychological barriers may increase

222 the risk of new ACL injury. To some extent, a degree of anxiety may be protective if

223 it means that athletes do not recklessly resume sports participation without undue

224 consideration for the health and function of their knee.

225 During the transition back to sport, athletes typically lack the support of a

226 rehabilitation professional, having already completed and been discharged from

227 rehabilitation months before. ${ }^{4}$ Therefore, this period might be considered critical for

228 the likelihood of successfully transitioning back to the previous level of sport. While

229 top athletes may have the resources to access psychological support during recovery

230 and rehabilitation, this type of support is not easily accessible for amateur athletes.

231 Hence, there is a need to develop easily accessible programs to address potentially

232 modifiable psychological factors that could conceivably impact on returning to sport. 
234 Evaluating aspects of cognitions, emotions and behaviour during sports injury

235 rehabilitation has been the focus of previous sports injury psychological research, and

236 a wide range of outcomes have been used to evaluate aspects including coping, ${ }^{58}$

237 emotions, ${ }^{34}$ mood, ${ }^{59}$ locus of control, ${ }^{60}$ and adherence to rehabilitation. ${ }^{61}$ There has

238 been less focus on the return to sport phase, although increasing research interest has

239 seen the recent development of scales that specifically focus on measuring

240 psychological factors during the return to sport. The Injury Psychological Readiness

241 to Return to Sport scale, ${ }^{62}$ Return to Sport after Serious Injury Questionnaire, ${ }^{63}$ and

242 Re-Injury Anxiety Inventory ${ }^{64}$ all focus on evaluating an athlete's confidence and

243 concerns with regard to their return to competition after athletic injury.

244 Two scales, which specifically focus on psychological factors and returning to sport

245 after ACL injury and reconstruction, have evidence of good validity. The ACL-Return

246 to Sport after Injury (ACL-RSI) scale ${ }^{54}$ was developed to evaluate psychological

247 readiness to return to sport after surgery. This 12-item scale addresses emotions, risk

248 appraisal and confidence in relation to returning to sport, ${ }^{54}$ and has been translated

249 from English to Swedish, ${ }^{65}$ French, ${ }^{66}$ and German ${ }^{67}$ languages. The Knee Self-

250 Efficacy scale ${ }^{68}$ (K-SES) was developed to prospectively evaluate an individual’s

251 perception of their ability to participate in physical activity as before their ACL

252 injury. This 22-item scale assesses activities of daily living, sport and recreational

253 activities, physical activities, and perceptions of knee function in the future. ${ }^{68}$

254 Among a range of sport-specific psychological measures, the ACL-RSI score,

255 measured before surgery and at 4 months after surgery, was found to be the best

256 predictor of returning to the pre-injury level sport at 1 year after ACL 
257 reconstruction. ${ }^{56}$ A recent study of Swedish recreational and competitive athletes

258 found that psychological readiness to return to sport, measured with the ACL-RSI,

259 was the psychological factor most strongly related to returning to the pre-injury

260 physical activity. ${ }^{49}$ Two studies have also reported ACL-RSI cut-off scores that

261 discriminated between athletes who subsequently did and did not return to their pre-

262 injury level sport after surgery. ${ }^{56,67}$ One study found a score of 51 points at 6 months

263 after ACL reconstruction (sensitivity 74\%, specificity 88\%) discriminated returners

264 and non-returners to sport at 7 months; ${ }^{67}$ while in the other study, a score of 56 points

265 at 4 months after surgery (sensitivity 58\%, specificity 83\%) was discriminative of

266 returning to sport at 1 year. ${ }^{56}$ Therefore, it may be possible that ACL-RSI scores

267 could be used to identify athletes who may be at risk of not returning to their pre-

268 injury level sport after ACL reconstruction.

269 Pre-operative K-SES scores were found to predict returning to the pre-injury intensity

270 and frequency of physical activity at 1 year following ACL reconstruction. ${ }^{69}$ Further,

271 K-SES scores also predicted muscle function and symptoms at 1 year after surgery. ${ }^{69}$

272 Our research group has also found that self-efficacy (measured with the K-SES) was

273 the psychological factor with the strongest association to satisfaction at 2 to 5 years

274 after ACL reconstruction (unpublished data). Self-efficacy has been shown to

275 improve with time during rehabilitation; men, those who were physically active at a

276 higher level before ACL injury, and those aged under 30 years reported higher pre-

277 operative self-efficacy compared to women, people who were active at a lower

278 intensity and people aged 30 years and over. ${ }^{44}$ 


\section{Conclusions}

280 Recovery from ACL injury and reconstruction is influenced by a multitude of

281 physical and non-physical factors. This review has demonstrated that psychological

282 factors influence the likelihood of injury, and the prognosis for recovery and returning

283 to sport following surgery. Therefore, the impact of psychological factors should not

284 be underestimated. The results of recent meta-analyses demonstrate moderate to large

285 effects for positive psychological factors favouring returning to the pre-injury level

286 following surgery. Therefore, there is a rationale for the re-evaluation of post-

287 operative rehabilitation programs to include interventions that systematically address

288 psychological factors, with the hypothesis that addressing these factors may improve

289 the return to sport after surgery.

290 Figure legend

291 Figure 1. Adapted biopsychosocial model of return to sport after injury

\section{References}

293

294

295

296

297

298

299

300

301

302

303

304

305

306

307

308

309

310

311

1. Majewski M, Susanne H, Klaus S: Epidemiology of athletic knee injuries: a 10year study. Knee 13:184-188, 2006.

2. Marx RG, Jones EC, Angel M, et al: Beliefs and attitudes of members of the American Academy of Orthopaedic Surgeons regarding the treatment of anterior cruciate ligament injury. Arthroscopy 19:762-770, 2003.

3. Renström P: Eight clinical conundrums relating to anterior cruciate ligament (ACL) injury in sport: recent evidence and a personal reflection. Br J Sports Med 47:367-372, 2013.

4. Myklebust $\mathrm{G}$, Bahr R: Return to play guidelines after anterior cruciate ligament surgery. Br J Sports Med 39:127-131, 2005.

5. Fowler P, Snyder-Mackler L: Commentary. J Orthop Sports Phys Ther 31:661, 2001.

6. Biggs A, Jenkins WL, Urch SE, et al: Rehabilitation for patients following ACL reconstruction: a knee symmetry model. N Am J Sports Phys Ther 4:2-12, 2009.

7. Feucht MJ, Cotic M, Saier T, et al: Patient expectations of primary and revision anterior cruciate ligament reconstruction. Knee Surg Sports Traumatol Arthrosc;10.1007/s00167-014-3364-z, 2014.

8. Matava MJ, Howard DR, Polakof L, et al: Public perception regarding anterior cruciate ligament reconstruction. J Bone Joint Surg Am 96:e85(81-86), 2014. 
9. Udry E, Shelbourne KD, Gray T: Psychological readiness for anterior cruciate ligament surgery: describing and comparing the adolescent and adult experiences. J Athl Train 38:167-171, 2003.

10. Kocher MS, Steadman JR, Briggs KK, et al: Relationships between objective assessment of ligament stability and subjective assessment of symptoms and function after anterior cruciate ligament reconstruction. Am J Sports Med 32:629634, 2004.

11. Medeni $\mathrm{O}$, Baltaci $\mathrm{G}$, Ozer $\mathrm{H}$ : Is there any correlation between functional and clinical tests in anterior cruciate ligament reconstructed knees after three years? MedicalExpress 1:22-26, 2014.

12. Ardern CL, Webster KE, Taylor NF, et al: Return to sport following anterior cruciate ligament reconstruction surgery: a systematic review and meta-analysis of the state of play. Br J Sports Med 45:596-606, 2011.

13. Ardern CL, Taylor NF, Feller JA, et al: Fifty-five per cent return to competitive sport following anterior cruciate ligament reconstruction surgery: an updated systematic review and meta-analysis including aspects of physical functioning and contextual factors. Br J Sports Med 48:1543-1552, 2014.

14. Johnston L, Carroll D: The context of emotional responses to athletic injury: a qualitative analysis. J Sport Rehabil 7:206-220, 1999.

15. Schwab Reese LM, Pittsinger R, Yang J: Effectiveness of psychological intervention following sport injury. J Sport Health Sci 1:71-79, 2012.

16. Podlog L, Heil J, Schulte S: Psychosocial factors in sports injury rehabilitation and return to play. Phys Med Rehabil Clin N Am 25:915-930, 2014.

17. Wiese-Bjornstal DM: Psychology and socioculture affect injury risk, response, and recovery in high-intensity athletes: a consensus statement. Scand J Med Sci Sports 20 (Suppl. 2):103-111, 2010.

18. Wiese-Bjornstal DM, Smith AM, Schaffer SM, et al: An integrated model of response to sport injury: psychological and sociological dynamics. J Appl Sport Psychol 10:46-69, 1998.

19. Ardern CL, Taylor NF, Feller JA, et al: A systematic review of the psychological factors associated with returning to sport following injury. Br J Sports Med 47:1120-1126, 2013.

20. Ivarsson A, Johnson U: Psychological factors as predictors of injuries among senior soccer players. A prospective study. J Sports Sci Med 9:347-352, 2010.

21. Ivarsson A, Johnson U, Podlog L: Psychological predictors of injury occurrence: a prospective investigation of professional Swedish soccer players. J Sport Rehabil 22:19-26, 2013.

22. Podlog L, Eklund R: The psychosocial aspects of a return to sport following serious injury: a review of the literature from a self-determination perspective. Psychol Sport Exerc 8:535-566, 2007.

23. McLean S, Clauw D, Abelson J: The development of persistent pain and psychological morbidity after motor vehicle collision: integrating the potential role of stress response systems into a biopsychosocial model. Psychosom Med 67:783-790, 2005.

24. Ardern CL: Anterior cruciate ligament reconstruction - not exactly a one-way ticket back to the preinjury level: a review of contextual factors affecting return to sport after surgery. Sports Health;10.1177/1941738115578131, 2015.

25. Czuppon S, Racette BA, Klein SE, et al: Variables associated with return to sport following anterior cruciate ligament reconstruction: a systematic review. $\mathrm{Br} J$ Sports Med 48:356-364, 2013. 
26. Everhart JS, Best TM, Flanigan DC: Psychological predictors of anterior cruciate ligament reconstruction outcomes: a systematic review. Knee Surg Sports Traumatol Arthrosc 23:752-762, 2015.

27. Brewer B, Andersen MB, van Raalte JL: Psychological aspects of sport injury rehabilitation: toward a biopsychosocial approach. In: Mostofsky DL, Zaichkowsky LD, eds. Medical and psychological aspects of sport and exercise. Morgantown, WV: Fitness Information Technology; 41-54 2002.

28. Brewer B: The role of psychological factors in sport injury rehabilitation outcomes. Int Rev Sport Exerc Psychol 3:40-61, 2010.

29. Andersen M, Williams J: A model of stress and athletic injury: prediction and prevention. J Sport Exerc Psychol 10:294-306, 1988.

30. Williams J, Andersen M: Psychosocial antecedents of sport injury: review and critique of the stress and injury model. J Appl Sport Psychol 10:5-25, 1998.

31. Benight C, Bandura A: Social cognitive theory of posttraumatic recovery: the role of perceived self-efficacy. Behav Res Ther 42:1129-1148, 2004.

32. Williams J, Andersen M: Psychosocial antecedents of sport injury and interventions for risk reduction. In: Tenenbaum G, Eklund R, eds. Handbook of sport psychology. 3rd ed. Hoboken, NJ: Wiley; 379-403 2007.

33. Williams J, Scherzer C: Injury risk and rehabilitation: psychological considerations. In: Williams J, ed. Applied sport psychology: personal growth to peak performance. 6th ed. New York: McGraw Hill Higher Education; 512-541 2010.

34. Morrey MA, Stuart MJ, Smith AM, et al: A longitudinal examination of athletes' emotional and cognitive responses to anterior cruciate ligament injury. Clin J Sports Med 9:63-69, 1999.

35. Walker N, Thatcher J, Lavallee D: Psychological responses to injury in competitive sport: a critical review. J R Soc Promot Health 127:174-180, 2007.

36. Ruddock-Hudson M, O'Halloran P, Murphy GC: Exploring psychological reactions to injury in the Australian Football League (AFL). J Appl Sport Psychol 24:375-390, 2012.

37. Langford J, Webster KE, Feller JA: A prospective longitudinal study to assess psychological changes following anterior cruciate ligament reconstruction surgery. Br J Sports Med 43:377-381, 2009.

38. Covassin T, Beidler E, Ostrowski J, et al: Psychosocial aspects of rehabilitation in sports. Clin Sports Med 34:199-212, 2015.

39. te Wierike SCM, van der Sluis A, van den Akker-Scheek I, et al: Psychosocial factors influencing the recovery of athletes with anterior cruciate ligament injury: a systematic review. Scand J Med Sci Sports 23:527-540, 2013.

40. Chmielewski TL, Zeppieri Jr G, Lentz TA, et al: Longitudinal changes in psychosocial factors and their association with knee pain and function after anterior cruciate ligament reconstruction. Phys Ther 91:1355-1366, 2011.

41. Kvist J: Rehabilitation following anterior cruciate ligament injury: current recommendations for sports participation. Sports Med 34:269-280, 2004.

42. Thomeé R, Kaplan Y, Kvist J, et al: Muscle strength and hop performance criteria prior to return to sports after ACL reconstruction. Knee Surg Sports Traumatol Arthrosc 19:1798-1805, 2011.

43. Nyland J, Brand E, Fisher B: Update on rehabilitation following ACL reconstruction. Open Access Journal of Sports Medicine 1:151-166, 2010. 
44. Thomeé $\mathrm{P}$, Währborg $\mathrm{P}$, Börjesson $\mathrm{M}$, et al: Self-efficacy, symptoms and physical activity in patients with an anterior cruciate ligament injury: a prospective study. Scand J Med Sci Sports 17:238-245, 2007.

45. Heijne A, Axelsson K, Werner S, et al: Rehabilitation and recovery after anterior cruciate ligament reconstruction: patients' experiences. Scand J Med Sci Sports 18:325-335, 2008.

46. Lynch AD, Logerstedt DS, Grindem $\mathrm{H}$, et al: Consensus criteria for defining 'successful outcome' after ACL injury and reconstruction: a Delaware-Oslo ACL cohort investigation. Br J Sports Med 49:335-342, 2015.

47. Ryan R, Deci E: Self-determination theory and the facilitation of intrinsic motivation, social development and well-being. Am Psychol 55:68-78, 2000.

48. Walker $\mathrm{N}$, Thatcher J: The emotional response to athletic injury. In: Thatcher J, Jones M, Lavallee D, eds. Coping and emotion in sport. 2nd ed. Hoboken: Routledge; 236-260 2012.

49. Ardern CL, Österberg A, Tagesson S, et al: The impact of psychological readiness to return to sport and recreational activities after anterior cruciate ligament reconstruction. Br J Sports Med 48:1613-1619, 2014.

50. Flanigan DC, Everhart JS, Pedroza A, et al: Fear of reinjury (kinesiophobia) and persistent knee symptoms are common factors for lack of return to sport after anterior cruciate ligament reconstruction. Arthroscopy 29:1322-1329, 2013.

51. Tjong VK, Murnaghan ML, Nyhof-Young JM, et al: A qualitative investigation of the decision to return to sport after anterior cruciate ligament reconstruction: to play or not to play. Am J Sports Med 42:336-342, 2014.

52. Kvist J, Ek A, Sporrstedt K, et al: Fear of re-injury: a hindrance for returning to sports after anterior cruciate ligament reconstruction. Knee Surg Sports Traumatol Arthrosc 13:393-397, 2005.

53. Kori SH, Miller RP, Todd DD: Kinesiophobia: a new view of chronic pain behaviour. Pain Manag 3:35-43, 1990.

54. Webster KE, Feller JA, Lambros C: Development and preliminary validation of a scale to measure the psychological impact of returning to sport following anterior cruciate ligament reconstruction surgery. Phys Ther Sport 9:9-15, 2008.

55. Podlog L, Banham SM, Wadey R, et al: Psychological readiness to return to competitive sport following injury: a qualitative study. Sport Psychol 29:1-14, 2015.

56. Ardern CL, Taylor NF, Feller JA, et al: Psychological responses matter in returning to preinjury level of sport after anterior cruciate ligament reconstruction surgery. Am J Sports Med 41:1549-1558, 2013.

57. Nyland J, Brand E: Psychological factors in the ACL reconstruction population: are they predictive of patient outcomes? In: Sanchis-Alfonso V, Monllau JC, eds. The ACL-Deficient Knee. London: Springer-Verlag; 189-199 2013.

58. Carver CS: You want to measure coping but your protocol's too long: consider the brief COPE. Int J Behav Med 4:92-100, 1997.

59. McNair D, Lorr M, Droppleman L: Edits manual for the Profile of Mood States. San Diego, CA: Educational and Industrial Testing Services; 1992.

60. Murphy GC, Foreman PE, Simpson CA, et al: The development of a locus of control measure predictive of injured athletes' adherence to treatment. J Sci Med Sport 2:145-152, 1999.

61. Brewer BW, Avondoglio JB, Cornelius AE, et al: Construct validity and interrater agreement of the Sport Injury Rehabilitation Adherence scale. $J$ Sport Rehabil 11:170-178, 2002. 
62. Glazer DD: Development and preliminary validation of the Injury-Psychological Readiness to Return to Sport (I-PRRS) scale. J Athl Train 44:185-189, 2009.

63. Podlog L, Eklund RC: Return to sport after serious injury: a retrospective examination of motivation and psychological outcomes. J Sport Rehabil 14:2034, 2005.

64. Walker N, Thatcher J, Lavallee D: A preliminary development of the Re-Injury Anxiety Inventory (RIAI). Phys Ther Sport 11:23-29, 2010.

65. Kvist J, Österberg A, Gauffin H, et al: Translation and measurement properties of the Swedish version of ACL-Return to Sports after Injury questionnaire. Scand $J$ Med Sci Sports 23:568-575, 2013.

66. Bohu Y, Klouche S, Lefevre N, et al: Translation, cross-cultural adaptation and validation of the French version of the Anterior Cruciate Ligament-Return to Sport after Injury (ACL-RSI) scale. Knee Surg Sports Traumatol Arthrosc 23:1192-1196, 2015.

67. Müller U, Schmidt M, Krüger-Franke M, et al: Die ACL-Return to Sport after Injury skala als wichtiger parameter bei der beurteilung rückkehr zum sport level I und II nach rekonstruktion des vorderen kreuzbands (deutsche version). Sport Orthop Traumatol 30:135-144, 2014.

68. Thomeé $\mathrm{P}$, Währborg $\mathrm{P}$, Börjesson $\mathrm{M}$, et al: A new instrument for measuring self-efficacy in patients with an anterior cruciate ligament injury. Scand J Med Sci Sports 16:181-187, 2006.

69. Thomeé $\mathrm{P}$, Währborg $\mathrm{P}$, Börjesson $\mathrm{M}$, et al: Self-efficacy of knee function as a pre-operative predictor of outcome 1 year after anterior cruciate ligament reconstruction. Knee Surg Sports Traumatol Arthrosc 16:118-127, 2008. 